\title{
Effects of Heart Rate Variability Coherence Biofeedback Training and Emotional Management Techniques to Decrease Music Performance Anxiety
}

\author{
Myron R. Thurber, PhD, ${ }^{1}$ Eugenia Bodenhamer-Davis, PhD, ${ }^{2}$ \\ Mark Johnson, ${ }^{2}$ Kris Chesky, PhD, ${ }^{2}$ and Cynthia K. Chandler, EdD ${ }^{2}$ \\ ${ }^{1}$ Neurotherapy Northwest. Spokane Valley, WA: ${ }^{2}$ University of North Texas, Denton. TX; \\ Keywords: performance anxiety, biofeedback, heart-rate variability, emwave ${ }^{\mathrm{m}}$, Freeze-Framer ${ }^{\mathrm{TM}}$
}

Due to the prevalence of music performance anxiety and the emergence of new biofeedback technologies used to decrease anxiety, student musicians were recruited to participate in an experimental repeated-measures study to identify effects of heart rate variability coherence biofeedback training and emotional self-regulation techniques on music performance anxiety and music performance. Fourteen students were assigned randomly to a treatment or control group following a 5-minute unaccompanied baseline performance. Treatment group participants received 4 5 heart rate variability training sessions of 30-50 minutes each. Training included bibliotherapy, computerized heart rate variability biofeedback training, emotional regulation exercises, and use of a portable heart rate variability training device. Measures included the State-Trait Anxiety Inventory, Performance Anxiety Inventory, Flow State Scale, average heart rate, and heart rate variability. Quade's rank-transformed analysis of covariance was used to evaluate treatment and no-treatment group comparisons. Combined music performance anxiety scores showed statistically significant improvement at a $\mathrm{p}=.05$ level with a large effect size of $\mathrm{np}^{2}=.320$. State anxiety measurement showed a large effect size of $\eta \mathrm{p}^{2}=.291$. The Performance Anxiety Inventory showed a large effect size of $\eta \mathrm{p}^{2}=.149$. Heart rate showed a large effect size of $\eta \mathrm{p}^{2}$ $=.143$. Heart rate variability showed statistical significance at $\mathrm{p}=.001$ level and a large effect size of $\eta \mathrm{p}^{2}=.698$. The treatment group average subjective decrease in music performance anxiety was $71 \%$, and the treatment group average subjective improvement in performance was $62 \%$. This study demonstrated statistical and practical/clinical significance of a relatively quick and inexpensive biofeedback training that had a large effect on decreasing mental, emotional, and physiological aspects of music performance anxiety and subjective improvement of performance for university students.

\section{Introduction}

\section{Music Performance Anxiety}

Though music performance anxiety (MPA) has been the focus of many studies, there is no clear definition of what constitutes MPA and little evidence for its prevalence or for effective treatments for its various components (McGinnis \& Milling, 2005). Therefore, the purpose of this study was to evaluate the effects of heart rate variability (HRV) biofeedback training on the mental, emotional, physiological, and performance aspects of MPA in university musicians.

One definition of music performance anxiety was given by Salmon (1990) as "the experience of persisting, distressful apprehension about and/or actual impairment of performance skills in a public context to a degree unwarranted given the individual's musical aptitude, training, and level of preparation" (p. 3). Psychological diagnostic criteria can be found in the Diagnostic and Statistical Manual of Mental Disorders Fourth Edition, Text Revision (DSM-IV-TR) (American Psychiatric Association, 2000). MPA meets the criteria for social phobia when it is marked with significant distress, anxiety, and/or avoidance in social or performance situations and the distress or anxiety is not due to other substances, medical, or psychological conditions (American Psychiatric Association, 2000). Though the DSM-IV-TR criteria for social phobia are clear, Osborne and Franklin (2002) reported that the DSM-IV criteria were met in only $27 \%$ of musicians reporting high levels of MPA. When Clark and Agras (1991) used a structured interview and surveyed potential participants for their study of MPA, only 2 of 94 participants met the DSM-III social phobia criteria when reporting that they experienced performance anxiety.

\section{Prevalence of MPA}

Lederman (1999) reported in his MPA literature review that the prevalence of MPA ranges from $16 \%-72 \%$ 


\begin{tabular}{|l|c|c|}
\hline Table 1 summay of treatments for stage & right \\
\hline & $\begin{array}{c}\text { Percentage } \\
\text { Tried, } \%\end{array}$ & $\begin{array}{c}\text { Success } \\
\text { Ratio, } \%\end{array}$ \\
\hline Prescribed medication & 40 & 92 \\
\hline Psychological counseling & 25 & 60 \\
\hline Aerobic exercise & 17 & 70 \\
\hline No treatment & 14 & 26 \\
\hline Hypnosis & 13 & 60 \\
\hline See general practitioner & 11 & 27 \\
\hline Yoga & 9 & 58 \\
\hline Nonprescription medication & 6 & 46 \\
\hline Alexander technique & 4 & 47 \\
\hline Massage therapy & 4 & 38 \\
\hline Rest/stop playing & 3 & 100 \\
\hline $\begin{array}{l}\text { Note. Adapted from Fishbein. } \\
\text { permission. }\end{array}$ & & \\
\hline
\end{tabular}

depending on the phrasing of questionnaires, context, and the person asking and answering the questions.

\section{Strategies for MPA}

The largest study on the array of treatments used by musicians for MPA was conducted by Fishbein, Middlestadt, Ottati, Straus, and Ellis (1988). Table 1 summarizes their findings for treatments used for stage fright and the effectiveness of those treatments.

A review of the literature by Lehrer on the effects of treatment for MPA revealed that beta blockers can reduce some of the physiological components of MPA, but do little to reduce the psychological components (Brantigan \& Brantigan, 1984; Lehrer, Vaschillo, \& Vaschillo, 2000). Beta blockers should be used only under medical supervision, according to Brantigan and Lehrer, and beta blockade drugs may be misused and overused (Brantigan \& Brantigan, 1984; Lehrer, et al., 2000). Some efficacy has been demonstrated with behavioral and cognitive-behavioral techniques, but no conclusion is available for cognitive therapy alone (Kenny, 2005). However, students and musicians in general do not actively seek cognitivebehavioral treatments (Brodsky, 1996). Studies on hypnosis, music therapy, and the Alexander technique are promising, but further research with larger samples are needed (Stanton, 1994). The studies on meditation and guided imagery alone showed no significant effect on MPA
(Chang, 2001; Esplen \& Hodnett, 1999). Electromyography and temperature training biofeedback have been effective when combined with other psychological interventions (Neimann, Pratt, \& Maughan, 1993). Electroencephalographic biofeedback, or neurofeedback, has been effective in improving performance quality, but further study is needed to demonstrate efficacy in reducing MPA (Egner \& Gruzelier, 2003).

\section{Components of MPA}

Components of MPA were reviewed by Salmon (1990), who reported, in a thorough literature review of the psychological perspective on MPA, that the most widely held model of anxiety, developed by Lang, purports that anxiety is the product of interaction among fearful thought, autonomic arousal, and behavioral responses to a perceived threat. Salmon (1990) also reported that Beck, a respected cognitive therapist, cited research that showed physiological arousal might initiate a chain reaction that leads to anxious thoughts. Miller and Chesky (2004) identified a complexity of MPA components, including a behavioral component, a physiological arousal component, and a cognitive-affective component that included the selfesteem of the performer.

Our study addressed the complexity of MPA through emotional management techniques to address the cognitive component, HRV coherence biofeedback training to address the psychophysiological components and emotional refocusing techniques along with visualization and mental rehearsal to address the cognitive behavioral components of MPA.

\section{HRV Training}

HRV biofeedback training is a noninvasive form of biofeedback that monitors the beat-to-beat changes in heart rate and displays this information in a graphic form for the participant to see and manipulate (Culbert, 2004).

Measurement of beat-to-beat changes are monitored through changes in pulse rate and can be derived from an electrocardiogram electrode placed on the chest, or a photoplethysmograph optical sensor placed on the ear or finger. Computerized programs can interpret the interbeat interval information into a spectral display of heart rhythm patterns (McCraty, 2002a). These patterns are accurate and powerfully display autonomic nervous system and psychophysiological function (McCraty \& Tomasino, 2006). Training consists of teaching the participant to decrease the chaotic or stress-related heart rhythm patterns, seen as jagged and unorganized patterns on the computer display, and to replace them with organized and smooth patterns 
(Culbert, 2004). Strategies may include relaxed and rhythmic breathing, letring go of stressful thoughts and feelings, and focusing on sustained neutral or positive emotions like appreciation or care (McCraty, 2002a). The smooth patterns of heart rhythms represent synchronized and organized communication and interaction among body systems such as autonomic function, breathing, blood pressure, heart rate, hormonal control, and brain waves. These synchronized patterns are said to be coherent (McCraty \& Childre, 2003). When coherence is raised to conscious awareness and is accompanied by effective emotional regulation there is a high degree of psychophysiological coherence, which is often accompanied by feelings of calmness, mental clarity, and ease (Childre \& Cryer, 2004; Tiller, McCraty, \& Atkinson, 1996). The simple act of identifying negative emotion and refocusing on positive emotions such as care or appreciation has been shown to increase psychophysiological balance or coherence (Nolan, 1998; McCraty, 2003). Once a person becomes aware of the feelings associated with high psychophysiological coherence and is able to access them first with and then without biofeedback assistance, they are achieving increased selfregulation often associated with improved health and performance (HeartMath, 2008).

Benefits of HRV training include improved cardiovascular function (Lehrer, 1987; McCraty, 2002b), decreased stress response (Nolan, 1998), improved mental function, and improved student performance on tests (Arguelles, McCraty, \& Rees, 2003). Researchers have shown the positive effects of HRV biofeedback training on stress response, anxiety similar to MPA, and depression (BarriosChoplin, McCraty, \& Cryer, 1997; Karavidas et al., 2007; McCraty, Atkinson, \& Tomasino, 2003; McCraty, Atkinson, Tomasino, Goelitz, \& Mayrovitz, 1999; McCraty, Tomasino, Atkinson, \& Sundream, 1999; Strack, 2003). Arguelles et al. (2003) reported that using HRV coherence biofeedback training in schools helped children reduce unhealthy patterns of behavior and thinking and establish a new pattern of physiological efficiency, mental acuity, and emotional stability.

A thorough literature review documents that HRV coherence training has not been systematically studied to verify its affects on music performance and MPA; therefore we decided to proceed with the following study.

\section{Methods}

\section{Design}

The study described below was approved through a university institutional review board and used an experi- mental repeated-measures research design to study the effects of training university student musicians with HRV coherence biofeedback and emotional shifting techniques to decrease MPA and improve music performance.

\section{Participants}

This study included 20 university musician volunteers recruited from two public universities in Texas. Five participants dropped out of the study due to schedule conflicts or illness, and one was dropped from the study due to taking beta blockers for high blood pressure, leaving seven each in the treatment and control groups. There were nine men and five women. The mean age was 23 years, and the age range was from 19 to 32 years. Of the participants, one identified ethnicity as African American, two as Asian, eight as White, two as Hispanic, and one as biracial. The group included nine undergraduates, two master's students, and three doctoral students. There were four voice performers, three who performed on piano, two on trumpet, one on flute, one on guitar, one on double bass, one on percussion, and one with a combination of guitar, drum, and voice.

\section{Assessment instruments}

Components of state and trait anxiety were assessed with the State-Trait Anxiety Inventory (STAI-Y) (Spielberger, Gorsuch, Lushene, Vagg, \& Jacobs, 1983). Components of performance were assessed using the Flow State Scale (FSS) (Jackson \& March, 1996). Components of MPA were evaluated using the Performance Anxiety Inventory (PAI) (Nagel, et al., 1989). Components of physiological stress response were measured using average heart rate and HRV (Barrios-Choplin, et al., 1997).

\section{Procedure}

\section{Participant Recruitment}

University student musicians were recruited from two local public universities through flyers placed in the practice rooms and music buildings, emails sent to music department faculty, and a 5-minute presentation given in different graduate and undergraduate music classes on the study and the type of treatment being used in it. Students also were recruited from undergraduate psychology classes where an incentive was offered by some teachers for extra credit if the students participated in the study as either a musician or an audience participant. All musicians, whether in the treatment or control group, were offered the opportunity to try the treatment and were paid $\$ 20$ when they completed the study. 


\section{Initial Assessment}

All participating students signed the informed consent, completed a demographic questionnaire as well as filled out a STAI-Y, FSS, and PAI, and were assessed for heart rate and HRV using the Freeze-Framer 2.0 (now known as the emWave $\mathrm{PC}$ ) interactive training software (HeartMath, 2005) for 7 minutes at the default challenge level 2 without the benefit of feedback. The measurement was taken using a photoplethysmograph ear clip. The students were instructed: "You are asked to sit quietly for the next 7 minutes while we measure your heart rate variability. During this time, please focus on the music you have chosen to perform as part of the study. Visualize yourself practicing and performing this piece of music." The participants were not able to see the computer screen and the auditory feedback sounds were muted so the participants were blind as to their HRV and heart rate. All participants were evaluated prior to being told their group assignments.

All participants were asked to perform a 5- to 7-minute piece of unaccompanied music in the performance phase of the study. They were told that the piece already should be familiar to them and be somewhat challenging for them. Performers understood that they would perform their piece of music in front of an unknown audience, and the procedures were explained. The participants also understood that they would perform the piece of music once before their group assignment and then 4 weeks later.

\section{First Performance}

Following the initial assessment, the participants signed up for their first and second performance times. The students were asked to commit to both the first and second performance times, which were scheduled 4 weeks apart on the same day of the week and at the same time. The performance hall used and order of individual performances were kept constant except for attrition of participants. The audiences varied in size berween 7 and 20 people. Prior to their performances, the participants had their heart rate and HRV assessed backstage in the performance hall, with the same instructions as in the initial assessment. They also filled out the state portion of the STAI-Y and the PAI. Immediately following their performances, the participants again had their heart rate and HRV taken with the same instructions and also filled out the FSS.

\section{Group Assignment}

Students were given a number in numerical sequence as they came for their initial assessment. Later, the student's numbers were drawn from a hat and alternately assigned to the treatment group or to the control group. Students were unaware of their assignment until after their first performance.

\section{Control Group}

Participants in the control group were asked to return in 4 weeks to perform the same musical piece, with no further instructions except for a phone call a few days before their second performance as a reminder of the performance.

\section{Treatment Group}

Following the first performance, participants assigned to the treatment group were asked to make an appointment to begin their training. Participants in the treatment group receivcd one-on-one training in HRV coherence biofeedback training and emotional refocusing techniques. The trainer was certified by the HeartMath Institute as a Qualified Resilient Educator Instructor and was certified by the Biofeedback Certification Institute of America in general biofeedback. The participants were trained using bibliotherapy (reading about stress physiology and coherence), computerized HRV biofeedback, and cognitive and emotional shifting techniques to improve psychophysiological coherence. The participants received between four and five training sessions one time per week for 30-50 minutes each. The goal was to train each participant to achieve a specific psychophysiological criterion. This criterion was operationalized for the particular HRV biofeedback software used and was defined as achieving the $80 \%$ combined medium and high coherence during cognitive rehearsal of performance scenarios for 7 minutes at the default challenge level 2, using an ear sensor and FreezeFrame 2.0 [emWave $\mathrm{PC}^{\otimes}$, without the benefit of any feedback. All participants met the training criteria by the end of the fourth session and were able to demonstrate and maintain a state of $80 \%$ medium to high psychophysiological coherence while focusing on the music they chose to perform as part of the study and visualization of practicing and performing that piece of music.

In all training sessions, the participants' heart rate and HRV coherence were assessed using the same procedure as in the initial assessment, both at the beginning and the end of the training session. During the first training session, the participants were given the booklet The Inside Story (HeartMath, 2002) and were instructed in the concepts of physiological arousal, how the brain processes anxious information, emotional memory, emotions and the nervous system, and the heart-brain connection. The concept of relaxed breathing at approximately six breaths per minute was introduced (Lehrer, et al. 2005). The participants observed their HRV and heart rate data using the FreezeFramer $^{\$ 2} 2.0$ software [emWave PC ${ }^{2}$ ] and were able to see 
the effects of changing their breathing and emotions on the computer screen. The participants also were given a copy of The Appreciative Heart (McCraty \& Childre, 2003) to read after the first session. By the second training session the participants were able to watch the computer screen and observe their HRV and improve their psychophysiological coherence through practicing the emotional refocusing technique of quick coherence as well as the Freeze-Framer techniques (HeartMath, 2005). In subsequent sessions, the participants continued to learn to improve their coherence by observing their $\mathrm{HRV}$ and were instructed and given cognitive rehearsal practice time while observing it. By the third session all participants were given an emWave Personal Stress Reliever 1.0 and instructed to continue practicing the emotional shifting, cognitive rehearsal, and HRV training and to use the small portable device in many different settings such as before music lessons, in practice rooms, in the performance hall before performances, and at home. The Coherence Coach ${ }^{\circ}$ software program accompanies the emWave unit, and some of the participants used that software at home as well to enhance their practice. The participants were given some individual interventions such as discussion of their experience of performance and stress and the role perfectionism and competition played in their MPA. Participants used the Freeze-Framer ${ }^{\otimes} 2.0$ [emWave PC ${ }^{\circledR}$ ] program during the in-clinic training and were trained at one of four different challenge levels using different training screens, depending on their current practice level and the success of the participant. The determination as to what challenge level and training screen to use was at the discretion of the trainer.

\section{Second Performance}

Three weeks following the initial performance, the participants returned to the same concert hall and performed the same musical number as in the initial performance with the same measures taken as in Performance 1. The participants then scheduled a final baseline and completed the same questionnaires as were done at the first performance. The participants also were scheduled to complete a final physiological baseline assessment.

\section{Final Physiological Baseline}

At the final baseline assessment, each participant completed the same questionnaires as were done at the initial baseline, with the addition of a questionnaire for the treatment group to rate on a Likert scale their impressions of how well the treatment improved their performance and decreased their MPA. All participants who completed the study were paid \$20, and those in the control group were given the opportunity to try HRV coherence biofeedback training.

\section{Results}

A combined MPA effect was assessed by deriving a combined standardized ranked score for all the measures given at pre- and postassessment. This combined standardized ranked score included the mental/emotional components of the STAI-Y, the PAI (with the physiological components of heart rate and HRV), and the performance component of the FSS. Effect size was assessed using SPSS $12.0 \mathrm{np}^{2}$ (SPSS Inc., Chicago, IL) and Cohen's description of $\eta^{2}$ effect size as $.0099=$ small, $.059=$ medium, and .13 $=$ large (Cohen, 1988). Alpha level was set at .05 consistent with social science research (Cohen).

\section{Data Analysis}

A Quade's rank-transformed analysis of covariance (ANCOVA) was used to establish standardized scores that could be combined to give a total look at mental, emotional, behavioral, and physiological aspects of MPA. The procedure for Quade's rank transformation according to Bonate $(2000)$ began with changing the raw pre- and posttest scores into rank pre- and posttest scores. Next, each ranked score was converted to a standardized deviation score by subtracting the pre- or posttest rank mean from each individual occasion score. An ANCOVA was then run using the posttest as the dependent variable and the pretest as the covariate on the standardized rank scores (Bonate, 2000).

Prior to Quade's rank transformation, the assumptions of independence through random assignment were met. Linearity was assessed and homogeneity of variance was met with a Levene's test (Field, 2000). Bonate (2000) described the Quade's rank transformation as robust against deviations of normality and assumptions such as linearity, homogeneity of variance, and homogeneity of regression slopes. Type I error rates are approximately $\alpha$ and remain robust against nonnormal data and data that violate homogeneity of within-group regression coefficients (Bonate, 2000).

Alpha level was set at .05 , consistent with social science research. Effect size was assessed using SPSS $12.0 \eta \mathrm{p}^{2}$ and Cohen's description of $\eta^{2}$ effect size as $.0099=$ small, .059 $=$ medium, and .13 = large (Cohen, 1988; Field, 2000).

\section{Combined MPA and Performance Scores}

The purpose of the comparison of pre- and posttreatment scores was to assess the combined aspects of mental/ 


\begin{tabular}{|c|c|c|c|c|c|c|c|c|}
\hline \multirow[b]{2}{*}{ Treatment Levels } & \multicolumn{4}{|c|}{ Prebaseline } & \multicolumn{4}{|c|}{ Postbaseline } \\
\hline & Mean & SD & Kurtosis & Skew & Mean & SD & Kurtosis & Skew \\
\hline Treatment group $(n=7)$ & -.928 & 19.32 & .276 & .800 & -6.50 & 16.98 & -.368 & .337 \\
\hline Control group $(n=7)$ & .928 & 13.64 & .139 & 1.170 & 6.50 & 13.18 & 2.212 & -1.559 \\
\hline
\end{tabular}

emotional stress, physiological stress response, and a performance rating into a composite score to see if $\mathrm{HRV}$ coherence biofeedback training would statistically or practically assist student musicians in decreasing MPA. Higher scores indicate greater MPA. Descriptive statistics for the standardized ranked scores data using SPSS 12.0 are summarized in Table 2.

An ANCOVA summary table shows that statistical significance was achieved at the .05 level. A large effect size also was achieved, indicating that the biofeedback and emotional refocusing techniques would account for a large portion of the difference between the scores of the treatment and the control groups. Summary of the results are given in Table 3.

\section{State Anxiety Assessment}

Analysis was run to see if state anxiety scores were similar between the treatment and control groups in the pre- and posttreatment musical performances. Higher scores indicate greater trait or state anxiety. Descriptive statistics for raw data trait anxiety using SPSS 12.0 are summarized in Table 4.

An ANCOVA summary table shows a large effect size was achieved, indicating that the biofeedback and emotional refocusing techniques would account for a large portion of the difference between the scores on state anxiety at baseline and before each performance between the treat- ment and control groups. Summary of the results are given in Table 5.

\section{Performance Anxiety Assessment}

The PAI was used to assess whether HRV coherence training would statistically or practically improve a student's experience of performance anxiety prior to a musical performance pre- and posttreatment. Higher scores on the PAI indicate more MPA. Descriptive statistics for raw data PAI data using SPSS 12.0 are summarized in Table 6.

An ANCOVA summary table shows a large effect size, indicating that the biofeedback and emotional refocusing techniques would account for a large portion of the difference between the scores on state anxiety at baseline and before each performance between the treatment and control groups. Summary of the results are given in Table 7.

\section{Average Heart Rate}

Repeated measures were used to assess whether HRV coherence biofeedback training would statistically and/or practically decrease a musician's heart rate prior to and following performances. The measures represent the sympathetic arousal of the autonomic nervous system and are an indication of psychophysiological coherence. Higher scores indicate greater physiological arousal and

\begin{tabular}{|c|c|c|c|c|c|c|}
\hline Source & sos & df & MS & $\boldsymbol{F}$ & Significance & $\eta p^{2}$ \\
\hline Covariate & 1767.353 & 1 & 1767.353 & 19.313 & .001 & .637 \\
\hline Group & 473.528 & 1 & 473.528 & 5.174 & $.044 * \star$ & $.320^{\mathrm{a}}$ \\
\hline Residual & 1006.647 & 11 & 91.513 & & & \\
\hline Total & 3247.528 & 13 & & & & \\
\hline \multicolumn{7}{|c|}{$\begin{array}{l}\left.{ }^{a} \eta p^{2}>.13=\text { large effect size (Cohen, } 1988\right) \text {. } \\
\because p<.05 . \\
\text { sOS = sum of squares; } d f=\text { degree of freedom; } M S=\text { mean square; } F=\text { estimates of a population variance; } \eta p^{2}=\text { effect } \\
\text { size as partial eta squared. }\end{array}$} \\
\hline
\end{tabular}




\begin{tabular}{|c|c|c|c|c|c|c|c|c|}
\hline \multirow[b]{2}{*}{ Treatment Levels } & \multicolumn{4}{|c|}{ Prebaseline } & \multicolumn{4}{|c|}{ Postbaseline } \\
\hline & Mean & SD & Kurtosis & Skew & Mean & SD & Kurtosis & Skew \\
\hline Treatment group $(n=7)$ & 39.42 & 11.67 & -1.04 & .767 & 31.85 & 7.75 & 2.00 & 1.39 \\
\hline
\end{tabular}

may indicate lower psychophysiological coherence. Descriptive statistics for raw heart rate data using SPSS 12.0 are summarized in Table 8.

An ANCOVA summary table shows a large effect size, indicating that the biofeedback and emotional refocusing techniques account for a large portion of the difference between repeated measures of heart rate. Summary of the results are given in Table 9.

\section{HRV Assessment}

Repeated measures were used to assess whether HRV coherence biofeedback training would statistically or practically improve a musician's HRV and the performer's psychophysiological coherence before performance. These measures represent the physiological arousal component of MPA. The statistical method used compared the pre- and posttraining baselines of all participants, specifically comparing the low coherence ratio of treatment versus control participants. Low coherence ratio scores indicated the percentage of total HRV that was outside of the preferred parameters of healthy HRV as defined by the Freeze-Framer $\left.\left.{ }^{(2 m W a v e ~} \mathrm{PC}^{(}\right)\right]$software program. Hence, the higher the (low coherence) score, the less preferable the HRV pattern (Culbert, 2004).

Coherence, in the software, is assessed from the interpolated interbeat interval time series from a moving average of a 64 -second long segment with a $50 \%$ overlap. The program calculates the power spectrum for each segment and determines the peak power ratio. The integral of peak power in the largest peak in the range $.04-.26 \mathrm{~Hz}$ is calculated, and the ratio of this peak power to total power minus peak power is determined. The average of ratios for the time series analyzed is the coherence measure for that series. The coherence ratio is sensitive to sustained coherent heart rhythms, and the units of power are standard units of HRV power spectrum analysis, $\mathrm{ms}^{2} / \mathrm{Hz}$. The coherence ratio $=($ Peak Power $) /$ (Total Power - Peak Power $)$.

Descriptive statistics for the raw HRV data using SPSS 12.0 are summarized in Table 10 . The mean prebaseline and postbaseline measures for the treatment group were 41.57 and 4.28 , respectively. This showed a decrease in the low coherence ratio and, inversely, an improvement in the participants' HRV as compared with the control group, whose mean scores were 54.85 prebaseline and 53.57 postbaseline, effectively showing little change pre- to postmeasurement.

An ANCOVA summary table shows statistical significance at the .001 level with a large effect size, indicating that the biofeedback and emotional refocusing techniques would account for a large portion of the difference between the scores on HRV between the treatment and the control group. Summary of the results are given in Table 11.

\begin{tabular}{|c|c|c|c|c|c|c|}
\hline Source & sos & $d f$ & MS & $\boldsymbol{F}$ & Significance & $\eta \mathfrak{p}^{2}$ \\
\hline Covariate & 40.528 & 1 & 40.528 & 3.484 & .089 & .241 \\
\hline Group & 52.599 & 1 & 52.599 & 4.521 & $.057^{\star}$ & $.291^{\mathrm{a}}$ \\
\hline Residual & 127.972 & 11 & 11.634 & & & \\
\hline Total & 221.099 & 13 & & & & \\
\hline \multicolumn{7}{|c|}{$\begin{array}{l}\left.{ }^{a} \eta p^{2}>.13=\text { large effect size (Cohen, } 1988\right) \\
{ }^{*} p<.10 . \\
\text { sOS = sum of squares; } d f=\text { degree of freedom; } M S=\text { mean square; } F=\text { estimates of a population variance; } \eta p^{2}=\text { effect } \\
\text { size as partial eta squared. }\end{array}$} \\
\hline
\end{tabular}




\begin{tabular}{|c|c|c|c|c|c|c|c|c|}
\hline \multirow[b]{2}{*}{ Treatment Levels } & \multicolumn{4}{|c|}{ Prebaseline } & \multicolumn{4}{|c|}{ Postbaseline } \\
\hline & Mean & SD & Kurtosis & Skew & Mean & SD & Kurtosis & Skew \\
\hline Treatment group $(n=7)$ & 46.00 & 14.68 & -.730 & .275 & 44.42 & 15.61 & -.593 & .375 \\
\hline Control group $(n=7)$ & 38.14 & 8.39 & -1.22 & -.845 & 38.85 & 8.09 & -1.525 & -.658 \\
\hline
\end{tabular}

\section{Average Subjective Self-Assessment of Treatment Effects}

Participants in the treatment group used a Likert scale to indicate their subjective perceptions of change in their first and second performances. A summary of the average perceived change is shown in Figure 1.

\section{Discussion}

The results of this study demonstrated that university student musicians can learn, with an average of four 30- to 50-minute sessions under a trained biofeedback practitioner, to use HRV coherence biofeedback and emotional shifting techniques to decrease MPA and improve their performance. No student in the treatment group showed a negative response to the training or an increase in the physiological measures of anxiety. All the treatment group students were able to meet the training criterion within four training sessions, and several met the criterion by the second training session. Several of the students requested to purchase the emWave Personal Stress Relievers they used in the study.

The analysis of the study results suggests that this training can be an effective tool to decrease scores on anxiety measures and subjectively increase students' performances while also lowering their average heart rate and improving their $\mathrm{HRV}$ and HRV coherence in live performance settings. The statistical analysis suggests that the treatment and control group scores were significantly different on a combined-scores measure of MPA at the .05 $\alpha$ level, with a $\eta p^{2}$ of .320 using the definition of $\eta p^{2}>.13$ $=$ large effect size (Cohen, 1988). Statistical significance at the $.001 \propto$ level also was reached in comparison of treatment and control group HRV and at the .10 level (.057) for state anxiety measured before pre- and posttreatment performances.

A large effect size $\left(\eta p^{2}>.13\right)$ was also found for the components of MPA: state anxiety, the PAI, average heart rate, and HRV. Average subjective improvement, reported by the treatment group members, indicated a $62 \%$ improvement in performance and a $71 \%$ decrease in performance anxiety.

Research participants reported taking no medications that would alter the data during the study; however, it was of interest to the researchers that the music students reported that their peers' often use beta blockers such as Inderal (propranolol) to control the physiological symptoms of anxiety during stressful music performances. Several students reported that at one time, they had borrowed medication and that it was not always under a doctor's prescription. The use of HRV coherence biofeedback and emotional refocusing techniques may be a good alternative to control MPA for music students who do not desire or are unable to use medication to manage it. The theories of Karl Pribram (1986) and other researchers may give us an idea why these techniques may be useful.

\begin{tabular}{|c|c|c|c|c|c|c|}
\hline Source & SOS & $d f$ & MS & $\boldsymbol{F}$ & Significance & $\eta p^{2}$ \\
\hline Covariate & 202.702 & 1 & 202.702 & 98.419 & .000 & .899 \\
\hline Group & 3.979 & 1 & 3.979 & 1.932 & .192 & $.149^{\mathrm{a}}$ \\
\hline Total & 229.336 & 13 & & & & \\
\hline $\begin{array}{l}{ }^{a} \eta \mathrm{p}^{2}> \\
\text { sos }=\mathrm{s} \\
\text { size as pal }\end{array}$ & $\begin{array}{l}\text { effect siz } \\
\text { res; df = } \\
\text { lared. }\end{array}$ & & $s=m e$ & $F=$ & a population & $0^{2}=$ \\
\hline
\end{tabular}




\begin{tabular}{|l|c|c|c|c|c|c|c|c|}
\hline \multirow{2}{*}{ Table 8. Heart rate descriptive statistics before rank transformation } & \multicolumn{3}{c|}{4} \\
Treatment Levels & \multicolumn{3}{|c|}{ Prebaseline } & \multicolumn{5}{c|}{ Postbaseline } \\
\cline { 2 - 11 } & Mean & SD & Kurtosis & Skew & Mean & SD & Kurtosis & Skew \\
\hline Treatment group $(n=7)$ & 78.85 & 7.86 & .955 & .767 & 75.00 & 4.43 & .592 & .000 \\
\hline Control group $(n=7)$ & 86.00 & 12.90 & -1.15 & .755 & 84.28 & 12.47 & .726 & .923 \\
\hline
\end{tabular}

\section{Emotional Management Techniques}

Research by Karl Pribram (1986), such as the holographic model of the mind/brain as well as his theory of emotion, helps describe emotional shifting and psychophysiological instrumentation to address emotional shifting techniques aided by biofeedback (Jackson \& March, 1996). Pribram (1986) stated that the brain is constantly sampling the internal and external environment for matching patterns. In his view, neither the structural cause-and-effect model nor the existential/phenomenological model of how the mind and perception work is sufficient. Pribram (1986) also stated that when changes to expected patterns are perceived (as in repeated music performance anxiety), regardless of whether the change is negative or positive, the mind, the senses, and the body systems are all alerted that a change from normal has occurred. This activates the body's alarm system, including emotions, physiological response, and perceptions. Previous beliefs that emotions are primarily the by-product of brain function have been replaced with a comprehensive view that the heart, brain, and body work in concert in response to stress from the internal and external environment (Nagel, et al., 1989). This would suggest that when working with performance anxiety, it is best to work with a comprehensive heart, brain, emotional, and perceptual approach rather than a single-modality approach.

Frederickson (2001) described affect as a general concept of consciously accessible feelings, and emotion as a subset of affective phenomena. He stated that the meaning individuals attach to events influences emotions and perceptions, and these perceptions and meanings trigger a cascade of responses such as subjective experience, facial expressions, cognitive processing, and physiological changes (Fredrickson, 2001). When a person is functioning at peak capacity, including mind, body, and energy, the perception is one of well-being and timelessness and has been described as "flow" (Csikszentmihalyi, 1990). The experience of flow is antithetical to performance anxiety and is a sought-after state by musicians who pursue excellence, self-regulation, optimism, and health (Jackson \& March, 1996; Seligman \& Csikszentmihalyi, 2000).

Our study attempted to help students achieve a sense of flow or peak performance by using HRV coherence biofeedback in conjunction with mental and emotional refocusing techniques that are compatible with the abovecited research.

A well-researched method for learning to achieve optimal and positive states of functioning, such as flow, is through HRV training and more specifically, coherence training using HRV to achieve "psychophysiological coherence" (McCraty \& Tomasino, 2006). Psychophysiological coherence is characterized by balance in the autonomic nervous system and heart-brain communication and facilitates cognitive function. In the coherent state, the emotions, perceptions, and heart-brain communication are synchronized in a joint time-frequency domain and increase cortical facilitation that enhances positive percep-

\begin{tabular}{|c|c|c|c|c|c|c|}
\hline Source & sos & $d f$ & MS & $F$ & Significance & $\eta p^{2}$ \\
\hline Covariate & .145 & 1 & .145 & .008 & .929 & .001 \\
\hline Group & 31.732 & 1 & 31.732 & 1.834 & .203 & $.143^{\mathrm{a}}$ \\
\hline Residual & 190.284 & 11 & 17.299 & & & \\
\hline Total & 222.161 & 13 & & & & \\
\hline \multicolumn{7}{|c|}{$\begin{array}{l}\left.{ }^{a} \eta p^{2}>.13=\text { large effect size (Cohen, } 1988\right) . \\
\text { soS = sum of squares; } d f=\text { degree of freedom; } M S=\text { mean square; } F=\text { estimates of a population variance; } \eta p^{2}=\text { effect } \\
\text { size as partial eta squared. }\end{array}$} \\
\hline
\end{tabular}




\begin{tabular}{|c|c|c|c|c|c|c|c|c|}
\hline \multirow[b]{2}{*}{ Treatment Levels } & \multicolumn{4}{|c|}{ Pre-Baseline } & \multicolumn{4}{|c|}{ Post-Baseline } \\
\hline & Mean & SD & Kurtosis & Skew & Mean & SD & Kurtosis & Skew \\
\hline Treatment group $(n=7)$ & 41.57 & 32.56 & -.109 & 1.221 & 4.28 & 8.05 & 5.65 & 2.33 \\
\hline Control group $(n=7)$ & 54.85 & 23.07 & -.994 & -.450 & 53.57 & 23.35 & -1.94 & -.134 \\
\hline
\end{tabular}

tion and decreases the fight-or-flight response when coupled with emotional refocusing tools (HeartMath, 2008).

The communication between the brain and the heart is transmitted neurologically via nerve impulses, biophysically though pulse wave, biochemically through hormones, and energetically though electromagnetic fields and then relayed to every cell of the body (Pribram, 1986). Bringing these different forms of psychophysiological communication into closer alignment or synchronicity enhances efficiency, increases a sense of well-being, promotes health, and improves cognitive function and performance (McCraty \& Tomasino, 2006)

\section{Limitations of the Study}

First, there was no sham study done to decrease the threat of placebo effects. Second, this research was limited by a small sample size of 14 , with seven each in the treatment and control groups. Six students left the study due to either schedule conflicts or the use of medication that interfered with accurate data collection. Another limitation was the varying size of the audiences during the performances. The research was conducted in the summer on a university campus; generalizability of findings to other populations of musicians is unknown. Limitations of instrumentation included using an ear-clip photoplethysmograph instead of a chest-placement electrocardiogram to gather HRV data (Giardino, Lehrer, \& Edelberg, 2002). Also, multiple sensors were used to accommodate the performance schedule of having performances back to back, so there could have been error from using different sensors, even though participants were randomly assigned to the sensor they used and maintained use of that sensor throughout the research project. Another limitation of the study is the possibility of Type I error due to multiple questionnaires used by the research team. Another was a lack of objective measures of performance to verify or refute the student musician's experience of his or her own performance as improved or not after treatment. Finally, the general field of study of MPA lacks a clear and measurable definition of what constitutes MPA.

\section{Practical implications}

In writing about their impressions of treatment effectiveness following the study, all of the students in the treatment group stated that they would recommend this training to other students. In a poststụdy questionnaire, students were asked to respond to the instruction: "Please, describe any other benefits you have received from the treatments." They responded with the following: (a) better prepared; (b) hope of being able to have focus during performances; (c) it made me more aware of the things I am

\begin{tabular}{|c|c|c|c|c|c|c|}
\hline Source & sos & $d f$ & MS & $\boldsymbol{F}$ & Significance & $\eta p^{2}$ \\
\hline Covariate & .075 & 1 & .075 & .018 & .912 & .001 \\
\hline Group & 149.715 & 1 & 149.715 & 25.478 & $.000^{\star \star \star}$ & $.698^{\mathrm{a}}$ \\
\hline Residual & 64.639 & 11 & 5.875 & & & \\
\hline Total & 214.429 & 13 & & & & \\
\hline
\end{tabular}




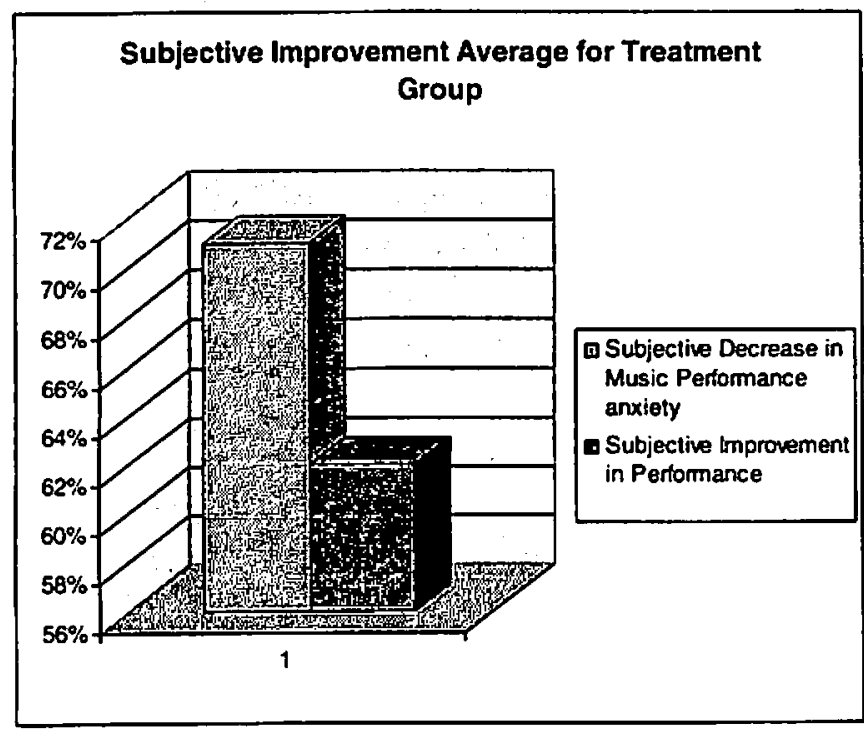

Figure. Average self-assessment of treatment effects.

doing during performance; (d) in general, I feel more calm; (e) I have been able to stay calm in situations where I normally would have gotten angry; I have also found myself taking deep breaths in stressful situations to help myself stay calm; (f) improved sleep; (g) I know a way that works to calm myself down; (h) awareness of the body's reactions to anxiety; and (i) generally relaxing.

The treatment participants also rated a statement on a 10point Likert scale: "How effective was the treatment (in) decreasing your performance anxiety?" The group average was 7.14 points on a scale of 0 (had no effect at all) to 10 (completely took away my anxiety). The treatment participants also rated "Did the treatment improve your musical performance?" The group average was 6.21 points on a scale of 0 (had no effect at all) to 10 (greatly improved; Figure...).

The technology, tools, and techniques used during this study are available through training from the Institute of HeartMath and its publications. Several universities and schools have established training labs where these techniques are taught to decrease test-taking anxiety and teach self-management skills. The cost is relatively inexpensive and students in general seem to be open to learning and applying the principles and techniques.

\section{Acknowledgments}

We wish to thank the University of North Texas for research support; The Institute of HeartMath and Dr. Rollin McCraty for editorial support; and doctoral students Svetlana Serova and Carol Mathers for their assistance in data collection. Also, thanks to the statistical support staff at the University of North Texas. We also acknowledge the help of the research staff at the Institute of HeartMath.

\section{References}

American Psychiatric Association. (2002). Diagnostic and statistical manual of mental disorders (4th ed., text revision). Washington, DC: Author.

Arguelles, L., McCraty, R., \& Rees, R. A. (2003). The heart in holistic education. Encounter, 16(3), 18-21.

Barrios-Choplin, B., McCraty, R., \& Cryer, B. (1997). An inner quality approach to reducing stress and improving physical and emotional well-being at work. Stress Medicine, 13, 193-201.

Bonate, P. L. (2000). Analysis of pretest-posttest designs. Boca Raton, FL: Chapman \& Hall/CRC.

Brantigan, T. A., \& Brantigan, C. O. (1984). Beta blockade and stage fright, looking back. ITG Journal, 8(4), 20-22.

Brodsky, W. (1996). Music performance anxiety reconceptualized: A critique of current research practices and findings. Medical Problems of Performing Artists, 113, 88-98.

Chang J. C. (2001). Effect of meditation on music performance anxiety. Dissertation Abstracts International. 62(5-A), 1765. (UMI No. 3014754).

Childre, D., \& Cryer, B. (2004). From chaos to coherence. Boulder Creek, CA: HeartMath.

Clark, D. B., \& Agras, W. S. (1991). The assessment and treatment of performance anxiety in musicians. American Journal of Psychiatry, 148, 598-605.

Cohen, J. (1998). Statistical power analysis for the behavioral sciences. Hillsdale, NJ: Lawrence Erlbaum.

Csikszentmihalyi, M. (1990). Flow: The psychology of optimal experience. New York: Harper \& Perennial.

Culbert, T. P. (2004). The practitioner's guide: Applications of the Freeze-Framer interactive learning system. Boulder Creek, CA: HeartMath.

Egner, T., \& Gruzelier, J. H. (2003). Ecological validity of neurofeedback: Modulation of slow wave EEG enhances musical performance. Cognitive Neuroscience and Neuropsychology, 14, 1221-1224.

Esplen, M. J., \& Hodnett, E. (1999). A pilot study investigating student musicians' experiences of guided imagery as a technique to manage performance anxiety. Medical Problems of Performing Artists, 15, 127-132.

Field, A. (2000). Discovering statistics using SPSS for Windows. London: Sage.

Fishbein, M., Middlestadt, S. E., Ottati, V., Straus, S., \& Ellis, A. (1988). Medical problems among ICSOM musicians: Overview of a national survey. Medical Problems of Performing Artists, 3, 1-8.

Fredrickson, B. L. (2001). The role of positive emotions in positive psychology. American Psychologist, 56, 218-226.

Giardino, N., Lehrer, P., \& Edelberg, R. (2002). A comparison of finger plethysmograph to ECG in the measurement of heart rate variability. Psychophysiology, 39, 246-253.

HeartMath. (2008). HeartMath interventions for counselors, therapists, social workers, and health care professionals. Boulder Creek, CA: Author.

HeartMath. (2005). Freeze-Framer 2.0. Boulder Creek, CA: Author (Intellectual property of Quantum Intech Inc.)

HeartMath (2002). The inside story. Boulder Creek, CA: Author.

Jackson, S. A., \& March, H. W. (1996). Development and validation of a scale to measure optimal experience: The flow state scale. Journal of Sports Exercise Psychology, 18, 17-35. 
Karavidas, M. K., Lehrer, P. M., Vaschillo, E., Vaschillo, B., Marin, H., Buyske, S., et al. (2007). Preliminary results of an open label study of heart rate variability biofeedback for the treatment of major depression. Applied Psychophysiology and Biofeedback, 32, 19-30.

Kenny, D. (2005). A systematic review of treatments for music performance anxiety. Anxiety. Stress \& Coping, 18, 183-209.

Lederman, R. J. (1999). Medical treatment of performance anxiety. Medical Problems of Performing Artists, 14, 117-121.

Lehrer, P. M., Vaschillo, E., \& Vaschillo, B. (2000). Resonant frequency biofeedback training to increase cardiac variability: Rationale and manual for training. Applied Psychophysiology and Biofeedback, 25, 177-191.

Lehrer, P. M. (1987). A review of the approaches to management of tension and performance anxiety in musical performance. Journal of Research in Music Education, 35, 143-152.

$\mathrm{McC}$ raty, R. (2003). Heart-brain neurodynamics: The making of emotions (Publication No. 03-01). Boulder Creek, CA: Institute of HeartMath, HeartMath Research Center.

McCraty, R. (2002). Heart rhythm coherence: An emerging area of biofeedback. Biofeedback, 30, 23-25.

MeCraty, R. (2002). Influence of cardiac afferent input on heartbrain synchronization and cognitive performance. International Journal of Psychophysiology, 45, 71-92.

McCraty, R., Atkinson, M., \& Tomasino, D. (2003). Impact of a workplace stress reduction program on blood pressure and emotional health in hypertensive employees. Journal of Alternative and Complementary Medicine, 9, 355-369.

McCraty, R., Atkinson, M., Tomasino, D., Goelitz, J., \& Mayrovitz, D. (1999). The impact of an emotional self-management skills course on psychosocial functioning and autonomic recovery to stress in middle school children. Integrative Physiological and Behavioural Science, 34, 246-268.

McCraty, R., \& Childre, D. (2003). The appreciative heart: The psychophysiology of positive emotions and optimal functioning (Publication No. 02-026). Boulder Creek, CA: Institute of HeartMath, HeartMath Research Center.

McCraty, R., \& Tomasino, D. (2006). Emotional stress, positive emotions, and psychophysiological coherence. In B. B. Arnetz \& R. Ekman (Eds.), Stress in Health and Disease (pp. 342364). Weinheim, Germany: Wiley-VCH.

McCraty, R., Tomasino, D., Atkinson, M., \& Sundream, J. S. (1999). Impact of the HeartMath self-management skills program on physiological and psychological stress in police officers. (Publication No. 99-075). Boulder Creek, CA: Institute of HeartMath, HeartMath Research Center.

McGinnis, A. M., \& Milling, L. S. (2005). Psychological treatment of musical performance anxiety: Current status and future direcrions. Psychotherapy, 42, 357-373.

Miller, S. R., \& Chesky, K. (2004). The multidimensional anxiety theory: An assessment of and relationships between intensity and direction of cognitive anxiety, somatic anxiety, and self-confidence over multiple performance requirements among college music majors. Medical Problems of Performing Artists, 19, 12-20.

Nagel, J. J., Himle, D. P., \& Papsdorf, J. D. (1989). Cognitivebehavioral treatment of musical performance anxiety. Psychology of Music, 17, 12-21.
Neimann, B. K., Pratt, R. R., \& Maughan, M. L. (1993). Biofeedback training, selected coping strategies and muscle relaxation interventions to reduce debilitative musical performance anxiety. Intermational Journal of Arts Medicine, 2(2), 7-15.

Nolan, R. (1998). Heart rate variability (Expert Series 4). Montreal, Quebec, Canada: ThoughtTechnology.

Osborne, M. S., \& Franklin, J. (2002). Cognitive processes in music performance anxiety. Australian Journal of Psychology. 54, 86-93.

Pribram, K. (1986). The cognitive revolution and mind/brain issues. American Psychologist, 41, 507-520.

Salmon, P. G. (1990). A psychological perspective on musical performance anxiety: A review of the literature. Medical Problems of Performing Artists, 5, 2-11.

Seligman, M. E., \& Csikszentmihalyi, M. (2000). Positive psychology. American Psychologist, 55, 5-14.

Spielberger, C. D., Gorsuch, R. L., Lushene, P. R., Vagg, P. R., \& Jacobs, G. A. (1983). State-trait anxiety inventory. Palo Alto, CA: Consulting Psychologist Press.

Stanton, H. E. (1994). Reduction of performance anxiety in music students. Australian Journal of Psychology, 29, 124-127.

Strack, B. W. (2003). Effect of heart rate variability (HRV) biofeedback on batting performance in baseball (Doctoral dissertation, Alliant International University, 2003). Dissertation Abstracts International, 64(3-B), 1540.

Tiller, W. A., McCraty, R., \& Atkinson, M. (1996). Cardiac coherence: A new, noninvasive measure of autonomic nervous system order. Alternative Therapies in Health and Medicine, 2, 1, 52-65.

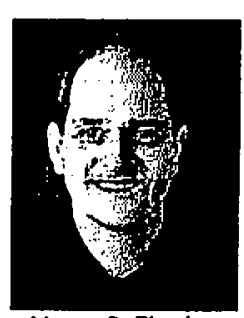

Myron R. Thurber
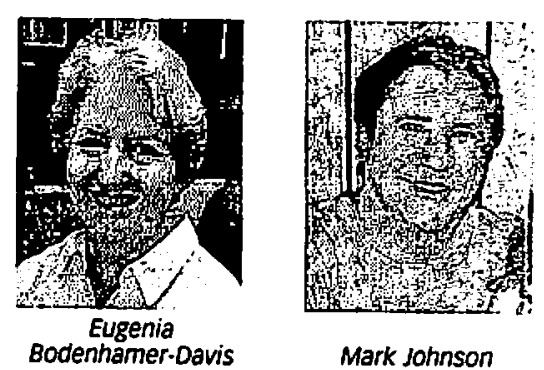

Mark Johnson
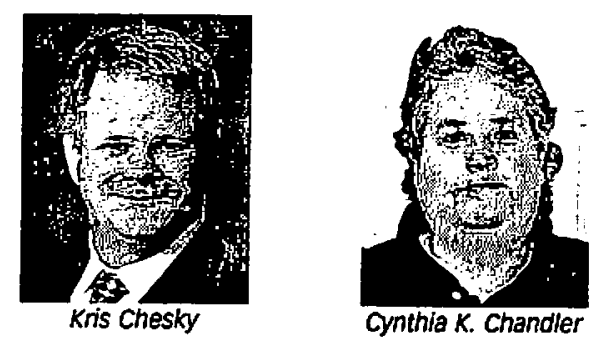

Correspondence: Myron Ross Thurber, PhD, PT, LMHC, NCC, BCIAC, BCIA-eeg. Neurotherapy Northwest, PO BOx 100, Spokane valley, WA 99037, email: mrthurberecomcast.net. 